\title{
Serum Vitamin D Level and Prehypertension among Subjects Free of Hypertension
}

\author{
Charumathi Sabanayagam ${ }^{a}$ Anoop Shankar ${ }^{a}$ \\ Shanmugasundaram Somasundaram ${ }^{b}$ \\ a Department of Community Medicine, West Virginia University School of Medicine, Morgantown, W. Va., USA; \\ ${ }^{b}$ Department of Cardiology, KS Hospital, Chennai, India
}

\section{Key Words}

Vitamin D $\cdot$ Blood pressure $\cdot$ Prehypertension

\begin{abstract}
Background: Low serum vitamin D levels are associated with high blood pressure (BP). Prehypertension is a preclinical stage where primary prevention efforts have been recommended for delaying or preventing the onset of hypertension. However, the majority of studies examining the association between vitamin D and BP have not accounted for kidney function or systemic inflammation. Methods: Participants of the 3rd National Health and Nutrition Examination Survey $>20$ years of age and free of hypertension $(n=9,215$, $53.5 \%$ women) and clinical cardiovascular disease were examined. Serum vitamin D levels were analyzed as quartiles. Prehypertension ( $\mathrm{n}=3,712$ ) was defined as systolic BP $120-$ $139 \mathrm{~mm} \mathrm{Hg}$ or diastolic BP 80-89 mm Hg. Results: Lower serum vitamin D levels were found to be associated with prehypertension independent of potential confounders including body mass index (BMI), serum cholesterol, C-reactive protein and estimated glomerular filtration rate. Compared to the highest quartile of serum vitamin D (referent), the odds ratio ( $95 \%$ confidence interval) of prehypertension associated with the lowest quartile was 1.48 (1.16-1.90; $p$ trend
\end{abstract}

$<0.0001)$. This association persisted in subgroup analyses by gender, race-ethnicity and BMI. Conclusion: Lower serum vitamin D levels are associated with prehypertension in a representative sample of US adults.

Copyright $\odot 2011$ S. Karger AG, Basel

A prevalence of low vitamin $\mathrm{D}$ status is common in the US [1]. Low serum levels of vitamin D are associated with an increased risk of diabetes and cardiovascular disease (CVD) [2, 3]. Recent epidemiological studies also suggest an inverse association between dietary or serum vitamin $\mathrm{D}$ measures and hypertension or high blood pressure (BP) [4-10]. However, these studies focused on specific population groups $[4,6,7]$, or were limited by the use of self-reported hypertension as the outcome $[4,5]$ or incomplete adjustment for lifestyle factors including smoking and alcohol consumption [8]. Reduced kidney function is an important confounder in the association between vitamin D and BP as it has been shown to be associated with both vitamin D [11] and high BP [12]. Similarly, markers of inflammation have been shown to be associated with both vitamin D $[13,14]$ and BP [13]. However, the majority of studies examining the association between vitamin D and BP have not accounted for kidney

\section{KARGER}

(C) 2011 S. Karger AG, Basel

Fax +41613061234

E-Mail karger@karger.ch

www.karger.com
Accessible online at:

www.karger.com/kbr
Dr. Anoop Shankar

Department of Medicine, West Virginia University School of Medicine

PO Box 9190

Morgantown, WV 26506-9190 (USA)

Tel. +1 304293 0199, E-Mail ashankar@hsc.wvu.edu 
function or systemic inflammation. Also, the previous literature is not entirely consistent as some recent studies did not find an independent association between vitamin $\mathrm{D}$ and BP after adjustment for potential confounders $[15,16]$.

Prehypertension is an earlier stage in the continuum of hypertension where prevention efforts have been recommended for delaying or preventing the onset of hypertension [17]. Prehypertension is shown to be associated with a twofold higher risk of CVD [18-20] in addition to a higher risk of developing hypertension [21]. In this context, we examined the association between serum vitamin $\mathrm{D}$ and prehypertension in a representative sample of US adults who were free of clinical CVD and hypertension after adjusting for important confounders, including estimated glomerular filtration rate (eGFR) and C-reactive protein (CRP) levels.

\section{Methods}

The data for the current study are derived from the 3rd National Health and Nutrition Examination Survey (NHANES III). Detailed description of the complex survey design and methods have been published elsewhere and are available online [22, 23]. In brief, NHANES employed a stratified, multistage, probability sample representative of the civilian non-institutionalized US population with oversampling of non-Hispanic blacks and Mexican Americans to ensure adequate representation of these groups. Eligible participants were required to sign an informed consent form and ethics approval was obtained from the Human Subjects Committee in the US Department of Health and Human Service.

The current study sample consisted of participants aged $>20$ years who were randomly assigned to be examined in the morning after an overnight fast. Serum vitamin D levels were measured in 18,883 participants who were examined in the morning after an overnight fast who had surplus sera available. We further excluded participants with hypertension $(n=6,059)$, self-reported CVD ( $\mathrm{n}=378)$, missing information on BP measurements $(\mathrm{n}=$ 2,957 ) and other relevant covariates included in the multivariable model $(n=274)$, leaving 9,215 participants for the current analysis of whom 3,712 had prehypertension.

\section{Measurement of Prehypertension}

Systolic and diastolic BP measurements were taken 3 times using a mercury sphygmomanometer according to the American Heart Association's recommendations during evaluation at the medical examination center [24]. The average of the 3 measures were taken as the systolic and diastolic BP. Patients were considered to have hypertension if they reported using current BP-reducing medication and/or had systolic BP $\geq 140 \mathrm{~mm} \mathrm{Hg}$ and/or diastolic $\mathrm{BP} \geq 90 \mathrm{~mm} \mathrm{Hg}$ [17]. We excluded those with hypertension in the current analysis. Prehypertension was defined as systolic BP 120-139 mm Hg or diastolic BP 80-89 mm Hg based on the 7th Report of the Joint National Committee on prevention, Detection, Evaluation, and treatment of High Blood Pressure recommendations [17].

\section{Measurement of Exposure}

Information on participant's demographic characteristics, educational attainment, cigarette smoking, alcohol consumption, physical activity, history of diabetes, hypertension and use of oral hypoglycemic drug or insulin administration, and antihypertensive medication use were assessed using a standardized questionnaire. Individuals who had smoked $<100$ cigarettes during their lifetime were considered never smokers, those who had smoked $\geq 100$ cigarettes lifetime and currently not smoking were considered former smokers, and those who had smoked $\geq 100$ cigarettes lifetime and currently smoking were considered current smokers. Current alcohol drinking was defined as consumption of $\geq 1$ alcoholic drink in the past month. Body mass index (BMI) was calculated as weight in kilograms divided by height in meters squared. Overweight was defined as a BMI between 25-29.9 and obesity as a BMI $\geq 30$.

Detailed descriptions of the blood collection, processing and quality control checks are provided in the Laboratory Procedures Manual [25]. Serum 25-hydroxy vitamin D was measured using a radioimmunoassay kit (Diasorin, Stillwater, Minn., USA) at the National Center for Environmental Health, CDC, Atlanta, Ga., USA [25]. The interassay CV was $15-25 \%$ for lower values $(20-62 \mathrm{nmol} / \mathrm{l})$ and $14-18 \%$ for higher values (86-143 nmol/l). Serum total cholesterol was measured enzymatically. Serum glucose was measured using the modified hexokinase method by the Diabetes Diagnostic Laboratory at University of Missouri. Diabetes was defined as a serum glucose $\geq 126 \mathrm{mg} / \mathrm{dl}$ after fasting for a minimum of $8 \mathrm{~h}$, a serum glucose $\geq 200 \mathrm{mg} /$ $\mathrm{dl}$ for those who fasted $<8 \mathrm{~h}$ before their NHANES visit, or a self-reported current use of oral hypoglycemic medication or insulin based on the recommendations of the American Diabetes Association [26]. CRP was analyzed using a modification of the Behring Latex-Enhanced CRP assay on the Behring Nephelometer Analyzer System. Serum creatinine was measured using a modified kinetic Jaffé reaction and GFR was estimated from serum creatinine using the Modification of Diet in Renal Disease equation [26].

\section{Statistical Analysis}

Serum levels of vitamin D were categorized into quartiles ( $\leq 17.7,17.8-24.6,24.7-32.4$ and $>32.4 \mathrm{ng} / \mathrm{ml}$ ). We compared selected baseline characteristics of the study population across quartiles of vitamin $\mathrm{D}$ by $\chi^{2}$ test or analysis of variance as appropriate. We calculated the odds ratio (OR) and 95\% confidence interval (CI) of prehypertension associated with quartiles of vitamin D using the highest quartile (quartile 4) as referent in two multivariable logistic regression models. In the first model, we adjusted for age (years) and gender (women, men) and in the second multivariable model, we additionally adjusted for raceethnicity (non-Hispanic whites, non-Hispanic blacks, Mexican Americans, others), smoking (never smoker, former smoker, current smoker), current alcohol intake (absent, present), body mass index, physical inactivity (absent, present), diabetes mellitus (absent, present), serum total cholesterol to high-density lipoprotein (HDL) cholesterol ratio, CRP (mg/dl), and eGFR $\left(\mathrm{ml} / \mathrm{min} / 1.73 \mathrm{~m}^{2}\right)$. Tests for linear trend were performed by modeling vitamin $\mathrm{D}$ quartiles as an ordinal variable in the corresponding multivariable logistic regression models. We also analyzed vitamin D as a continuous variable (per standard deviation [SD] change). To examine the consistency of the asso- 
Table 1. Baseline characteristics of the study population by quartiles of vitamin $\mathrm{D}$

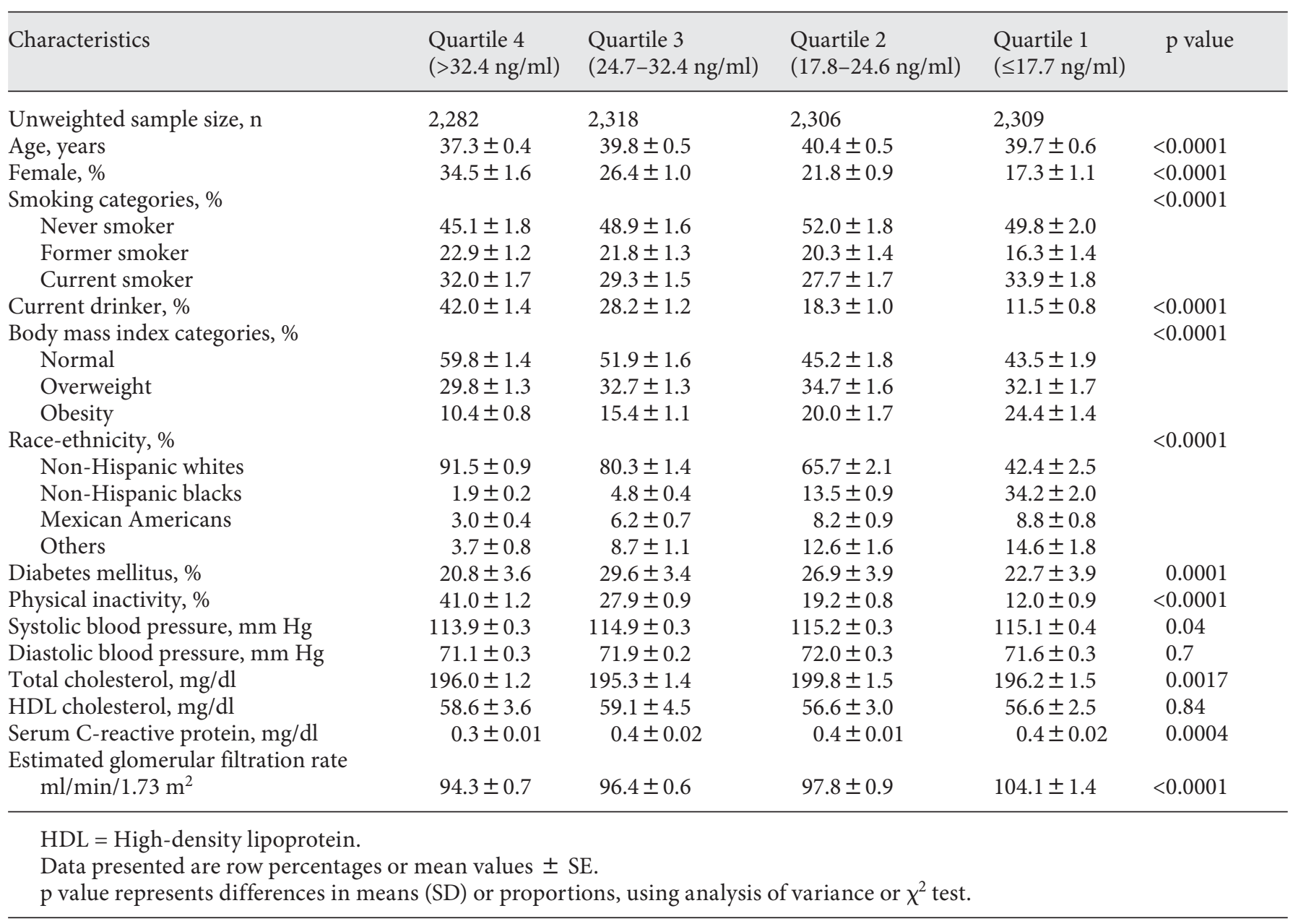

ciation between vitamin $\mathrm{D}$ and prehypertension, we then performed subgroup analyses stratified by gender, race-ethnicity and BMI. Interactions were formally evaluated by including cross-product interaction terms in the corresponding multivariable models. To examine the dose-response relationship of the observed association between serum vitamin $\mathrm{D}$ level and prehypertension without linearity assumptions, we used flexible nonparametric logistic regression employing the generalized additive modeling approach [R system for statistical computing, available from Comprehensive R Archive Network (http://www. CRAN.R-project.org)] to calculate odds of prehypertension, adjusting for all covariates in the multivariable model; the predicted odds of prehypertension were then plotted against increasing vitamin D levels (on the log scale). All analyses were conducted by including sampling weights [23] to account for unequal probabilities of selection, oversampling, and non-response using SUDAAN (version 8.0; Research Triangle Institute, Research Triangle Park, N.C., USA) and SAS (version 9.2; SAS Institute, Cary, N.C., USA) software. Standard errors (SEs) were estimated using the Taylor series linearization method.

\section{Results}

Table 1 shows the baseline characteristics of the study population. Those in the lowest quartile of vitamin D were more likely to be older, current smokers, obese, have higher levels of systolic BP, total cholesterol, CRP, eGFR; and less likely to be female, non-Hispanic white, current drinkers and physically inactive.

Table 2 shows the association between serum vitamin $\mathrm{D}$ levels and prehypertension. Lower levels of vitamin $\mathrm{D}$ were positively associated with prehypertension in both the age- and gender-adjusted and the multivariable model. Models evaluating trend in this association were also statistically significant $(\mathrm{p}<0.001)$. This positive association persisted when serum vitamin $\mathrm{D}$ was analyzed as a continuous variable. 
Table 2. Association between vitamin $\mathrm{D}$ and prehypertension

\begin{tabular}{lccc}
\hline Vitamin D quartiles & $\mathrm{n}$ (cases) $^{\mathrm{a}}$ & $\begin{array}{l}\text { Age-, gender-adjusted } \\
\text { OR }(95 \% \mathrm{CI})^{\mathrm{b}}\end{array}$ & $\begin{array}{l}\text { Multivariate } \\
\text { OR }(95 \% \mathrm{CI})^{\mathrm{b}, \mathrm{c}}\end{array}$ \\
\hline Quartile 4 $(>32.4 \mathrm{ng} / \mathrm{ml})$ & $2,282(923)$ & $1.00($ referent $)$ & 1.00 (referent) \\
Quartile 3 $(24.7-32.4 \mathrm{ng} / \mathrm{ml})$ & $2,318(928)$ & $1.20(0.97-1.48)$ & $1.14(0.91-1.43)$ \\
Quartile 2 $(17.8-24.6 \mathrm{ng} / \mathrm{ml})$ & $2,306(955)$ & $1.36(1.17-1.58)$ & $1.25(1.06-1.48)$ \\
Quartile 1 $(\leq 17.7 \mathrm{ng} / \mathrm{ml})$ & $2,309(906)$ & $1.58(1.29-1.93)$ & $1.48(1.16-1.90)$ \\
p (trend) & & $<0.0001$ & $<0.0001$ \\
Per SD decrease in vitamin D $(11.4 \mathrm{ng} / \mathrm{ml})$ & $9,215(3,712)$ & $1.18(1.09-1.27)$ & $1.14(1.05-1.24)$ \\
\hline
\end{tabular}

${ }^{a}$ Unweighted sample size.

b OR $(95 \%$ CI $)=$ Odds ratio $(95 \%$ confidence interval) from weighted analysis.

${ }^{c}$ Adjusted for age (years), gender (women, men), race-ethnicity (non-Hispanic whites, non-Hispanic blacks, Mexican Americans, others), smoking categories (never, former, current), current drinker (absent, present), body mass index categories $(<25,25-29, \geq 30)$, physical inactivity (absent, present), diabetes (absent, present), total to high-density lipoprotein cholesterol ratio, C-reactive protein level (mg/dl), and estimated glomerular filtration rate $\left(\mathrm{ml} / \mathrm{min} / 1.73 \mathrm{~m}^{2}\right)$.

Table 3. Association between vitamin $\mathrm{D}$ and prehypertension by gender

\begin{tabular}{|c|c|c|c|}
\hline Vitamin D quartiles & $\mathrm{n}(\text { cases })^{\mathrm{a}}$ & $\begin{array}{l}\text { Age-, gender-adjusted } \\
\text { OR }(95 \% \mathrm{CI})^{\mathrm{b}}\end{array}$ & $\begin{array}{l}\text { Multivariate } \\
\text { OR }(95 \% \mathrm{CI})^{\mathrm{b}, \mathrm{c}}\end{array}$ \\
\hline \multicolumn{4}{|l|}{$\operatorname{Men}(\mathrm{n}=4,289)$} \\
\hline Quartile $4(>32.4 \mathrm{ng} / \mathrm{ml})$ & $1,242(657)$ & 1.00 (referent) & 1.00 (referent) \\
\hline Quartile $3(24.7-32.4 \mathrm{ng} / \mathrm{ml})$ & $1,207(629)$ & $1.06(0.79-1.43)$ & $1.07(0.80-1.44)$ \\
\hline Quartile $2(17.8-24.6 \mathrm{ng} / \mathrm{ml})$ & $1,040(566)$ & $1.27(1.02-1.57)$ & $1.28(0.98-1.66)$ \\
\hline Quartile $1(\leq 17.7 \mathrm{ng} / \mathrm{ml})$ & $800(459)$ & $1.47(1.10-1.95)$ & $1.53(1.13-2.07)$ \\
\hline $\mathrm{p}($ trend $)$ & & 0.001 & 0.004 \\
\hline \multicolumn{4}{|l|}{ Women $(\mathrm{n}=4,926)$} \\
\hline Quartile $4(>32.4 \mathrm{ng} / \mathrm{ml})$ & $1,067(249)$ & 1.00 (referent) & 1.00 (referent) \\
\hline Quartile $3(24.7-32.4 \mathrm{ng} / \mathrm{ml})$ & $1,099(326)$ & $1.42(1.07-1.88)$ & $1.19(0.89-1.61)$ \\
\hline Quartile $2(17.8-24.6 \mathrm{ng} / \mathrm{ml})$ & $1,278(362)$ & $1.53(1.18-1.99)$ & $1.23(0.93-1.62)$ \\
\hline Quartile $1(\leq 17.7 \mathrm{ng} / \mathrm{ml})$ & $1,482(464)$ & $1.75(1.31-2.34)$ & $1.44(1.03-2.00)$ \\
\hline $\mathrm{p}($ trend $)$ & & $<0.0001$ & 0.03 \\
\hline \multicolumn{4}{|c|}{$\begin{array}{l}\text { a Unweighted sample size. } \\
{ }^{b} \text { OR }(95 \% \mathrm{CI})=\text { Odds ratio ( } 95 \% \text { confidence interval) from weighted analysis. } \\
{ }^{c} \text { Adjusted for age (years), race-ethnicity (non-Hispanic whites, non-Hispanic blacks, Hispanic-Americans, } \\
\text { thers), smoking categories (never, former, current), current drinker (absent, present), body mass index catego- } \\
\text { es }(<25,25-29, \geq 30 \text { ), physical inactivity (absent, present), diabetes (absent, present), total to high-density lipo- } \\
\left.\text { rotein cholesterol ratio, C-reactive protein (mg/dl), and estimated glomerular filtration rate (ml } / \mathrm{min} / 1.73 \mathrm{~m}^{2}\right) \text {; } \\
\text { interaction (vitamin D quartiles } \times \text { female) was } 0.84 \text {. }\end{array}$} \\
\hline
\end{tabular}

In subgroup analyses, the positive association between lower levels of vitamin D and prehypertension was consistently present among categories of gender (table 3), race-ethnicity (table 4) and BMI (table 5). No significant interactions were detected between vitamin $\mathrm{D}$ and gender, race-ethnicity or BMI ( $p$ interaction $>0.1$ ). When we employed nonparametric models to graphically examine the dose-response relationship between serum vitamin D levels and prehypertension without linearity assumptions involved in traditional regression models, we observed a continuous inverse association between serum vitamin $\mathrm{D}$ level and prehypertension without any threshold effect (fig. 1). 
Fig. 1. Vitamin D and prehypertension. Multivariable-adjusted odds of prehypertension according to serum vitamin D level (ng/ $\mathrm{ml}$ ). The solid thick line represents the predicted odds of prehypertension from nonparametric logistic regression; the dashed lines indicate $95 \%$ confidence limits for the nonparametric logistic regression estimates. The nonparametric logistic regression was adjusted for age (years), gender (men, women), race-ethnicity (non-Hispanic whites, non-Hispanic blacks, Mexican Americans, others), smoking categories (never, former, current), current drinker (absent, present), body mass index categories $(<25$, $25-29, \geq 30$ ), physical inactivity (absent, present), diabetes (absent, present), total to high-density lipoprotein cholesterol ratio, C-reactive protein level ( $\mathrm{mg} / \mathrm{dl})$, and estimated glomerular filtration rate $\left(\mathrm{ml} / \mathrm{min} / 1.73 \mathrm{~m}^{2}\right)$. X axis = Serum vitamin D level (ng/ $\mathrm{ml}$ ); $\mathrm{Y} 1$ axis = predicted odds of prehypertension plotted in log scale; Y2 axis = participant number for each serum vitamin D level.

\section{Discussion}

Lower serum levels of vitamin D were found to be positively associated with prehypertension in a nationally representative sample of US adults free of hypertension and CVD. This association was independent of age, gender, race-ethnicity, smoking, alcohol consumption, physical inactivity, BMI, diabetes, total cholesterol to HDL ratio, CRP and eGFR, and was consistently present within categories of gender, race-ethnicity and BMI. Further, the association between low vitamin $\mathrm{D}$ and prehypertension was present without a threshold effect when vitamin $D$ was analyzed as a continuous variable in nonparametric graphical models. In addition, we were able to adjust for low kidney function and systemic inflammation, factors that could potentially confound the association between vitamin $\mathrm{D}$ and $\mathrm{BP}$.

Serum 25-hydroxy vitamin D, the active metabolite of circulating vitamin $\mathrm{D}$, reflects the cumulative exposure to sunlight and dietary vitamin D [27]. Our finding of an association between low serum vitamin $\mathrm{D}$ and prehypertension is largely consistent with previous cohort and cross-sectional studies that examined the association between vitamin $\mathrm{D}$ and hypertension or $\mathrm{BP}$ in the US [4-6, 8] and Europe [28-31] and extend the association to prehypertension, an earlier stage when primary prevention is effective. In the US, Zhao et al. [9] in a recent study reported a positive association between vitamin D and hypertension, and prehypertension. Forman et al. $[4,5]$ reported a significant positive association

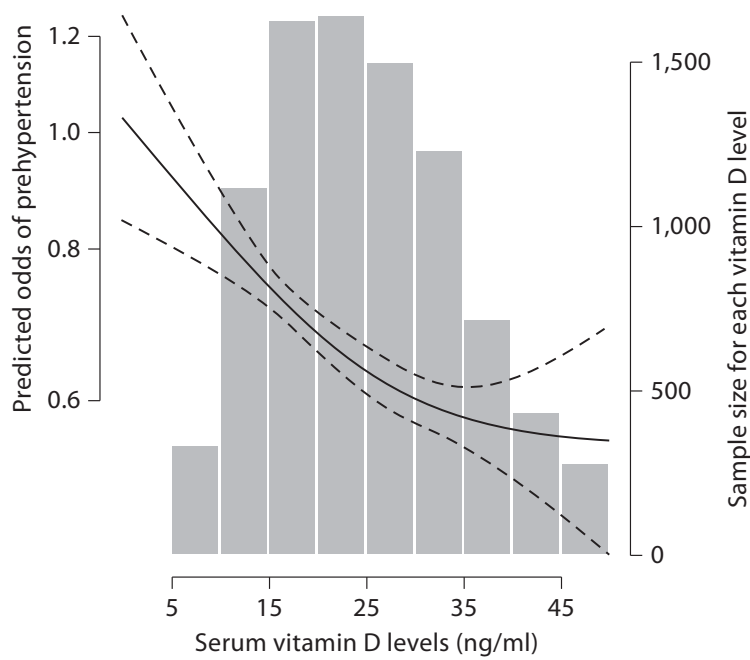

between dietary vitamin $\mathrm{D}$ and self-reported incident hypertension among 38,388 men from the Health Professional' Follow-Up Study and 77,531 women from the Nurses' Health Study; a positive association was also reported between serum vitamin D and incident hypertension in a subsample of participants. Further, a nested case-control study from the 2nd Nurses' Health Study reported a positive association between serum vitamin $\mathrm{D}$ and incident hypertension among 1,484 healthy, young, white women [4]. In the NHANES, systolic BP was shown to be inversely associated with vitamin $\mathrm{D}$ among 12,644 participants [8] and in a subgroup of white participants [6]. However, not all studies have shown a consistent positive association between low vitamin D and BP. In a prospective study conducted in the UK, Forouhi et al. [15] did not find a significant association between serum vitamin D and BP in a middleaged cohort of 524 non-diabetic men and women in a 10 -year follow-up. In another prospective study conducted by Jorde et al. [31] serum vitamin D levels were strongly associated with systolic BP but had no predictive value for the development of hypertension or changes in BP. Few intervention trials have reported that vitamin D supplementation did not reduce BP in specific populations including postmenopausal [32] and overweight subjects [33].

Several mechanisms have been proposed to explain the association between low levels of vitamin $\mathrm{D}$ and prehypertension. Animal studies have shown increased activation of the renin-angiotensin-aldosterone system in 
vitamin $\mathrm{D}$ receptor and 1-hydroxylase knockout mice $[34,35]$. Low vitamin $\mathrm{D}$ also promotes insulin resistance [36], endothelial dysfunction [37], proinflammatory cytokine production [38], and secondary hyperparathyroidism and hypocalcemia affecting vascular smooth muscles [39]. Our finding of an association between low vitamin $\mathrm{D}$ and prehypertension is also analogous to an association between low vitamin $\mathrm{D}$ and preeclampsia among pregnant women [40].

The main strengths of the study include its population-based nature, rigorous methodology, and rich information on covariates. The cross-sectional nature of the study limits making causal inferences. Further, we do not have information on parathyroid hormone which could confound the observed association.
In summary, in a representative sample of US adults, low serum levels of vitamin D were found to be positively associated with prehypertension independent of potential confounding factors, including BMI, serum cholesterol, CRP, and eGFR. Since prehypertension is a stage in the disease continuum where hypertension prevention has been shown to be effective [17], future intervention trials could clarify if vitamin D supplementation at this stage can prevent or delay the onset of hypertension in the general population.

\section{Acknowledgement}

This study was funded by an American Heart Association National Clinical Research program grant and NIEHS grant 5-R03ES0018888-02 (A.S.).

\section{References}

1 Lee JH, O’Keefe JH, Bell D, Hensrud DD, Holick MF: Vitamin D Deficiency: An important, common, and easily treatable cardiovascular risk factor? J Am Coll Cardiol 2008;52:1949-1956.

2 Baz-Hecht M, Goldfine AB: The impact of vitamin $\mathrm{D}$ deficiency on diabetes and cardiovascular risk. Curr Opin Endocrinol Diabetes Obes 2010;17:113-119.

$\checkmark 3$ Wang TJ, Pencina MJ, Booth SL, et al: Vitamin D deficiency and risk of cardiovascular disease. Circulation 2008;117:503-511.

4 Forman JP, Curhan GC, Taylor EN: Plasma 25-hydroxyvitamin D levels and risk of incident hypertension among young women. Hypertension 2008;52:828-832.

$\checkmark 5$ Forman JP, Giovannucci E, Holmes MD, et al: Plasma 25-hydroxyvitamin D levels and risk of incident hypertension. Hypertension 2007;49:1063-1069.

-6 Judd SE, Nanes MS, Ziegler TR, Wilson PW, Tangpricha V: Optimal vitamin D status attenuates the age-associated increase in systolic blood pressure in white Americans: results from the Third National Health and Nutrition Examination Survey. Am J Clin Nutr 2008;87:136-141.

7 Schmitz KJ, Skinner HG, Bautista LE, et al: Association of 25-hydroxyvitamin D with blood pressure in predominantly 25-hydroxyvitamin D deficient Hispanic and African Americans. Am J Hypertens 2009;22: 867-870.

8 Scragg R, Sowers M, Bell C: Serum 25-hydroxyvitamin $\mathrm{D}$, ethnicity, and blood pressure in the Third National Health and Nutrition Examination Survey. Am J Hypertens 2007;20:713-719.
9 Zhao G, Ford ES, Li C, Kris-Etherton PM, Etherton TD, Balluz LS: Independent associations of serum concentrations of 25-hydroxyvitamin $\mathrm{D}$ and parathyroid hormone with blood pressure among US adults. J Hypertens 2010;28:1821-1828.

10 Gupta AK, Brashear MM, Johnson WD: Prediabetes and prehypertension in healthy adults are associated with low vitamin D levels. Diabetes Care 2011;34:658-660.

11 Chonchol M, Scragg R: 25-Hydroxyvitamin $\mathrm{D}$, insulin resistance, and kidney function in the Third National Health and Nutrition Examination Survey. Kidney Int 2007;71:134139.

12 Barri YM: Hypertension and kidney disease: a deadly connection. Curr Cardiol Rep 2006; 8:411-417.

-13 Sesso HD, Buring JE, Rifai N, Blake GJ, Gaziano JM, Ridker PM: C-Reactive protein and the risk of developing hypertension. JAMA 2003;290:2945-2951.

14 Nagpal S, Na S, Rathnachalam R: Noncalcemic actions of vitamin $\mathrm{D}$ receptor ligands. Endocr Rev 2005;26:662-687.

15 Forouhi NG, Luan J, Cooper A, Boucher BJ, Wareham NJ: Baseline serum 25-hydroxy vitamin D is predictive of future glycemic status and insulin resistance: the Medical Research Council Ely Prospective Study 19902000. Diabetes 2008;57:2619-2625.

16 Jorde R, Figenschau Y, Emaus N, Hutchinson M, Grimnes G: Serum 25-hydroxyvitamin D levels are strongly related to systolic blood pressure but do not predict future hypertension. Hypertension 2010;55:792-798.
17 Chobanian AV, Bakris GL, Black HR, et al: The Seventh Report of the Joint National Committee on Prevention, Detection, Evaluation, and Treatment of High Blood Pressure: the JNC 7 report. JAMA 2003;289: 2560-2572.

18 Liszka HA, Mainous AG, III, King DE, Everett CJ, Egan BM: Prehypertension and cardiovascular morbidity. Ann Fam Med 2005; 3:294-299.

19 Vasan RS, Larson MG, Leip EP, et al: Impact of high-normal blood pressure on the risk of cardiovascular disease. N Engl J Med 2001; 345:1291-1297.

-20 Gupta AK, McGlone M, Greenway FL, Johnson WD: Prehypertension in disease-free adults: a marker for an adverse cardiometabolic risk profile. Hypertens Res 2010;33: 905-910.

21 Vasan RS, Larson MG, Leip EP, Kannel WB, Levy D: Assessment of frequency of progression to hypertension in non-hypertensive participants in the Framingham Heart Study: a cohort study. Lancet 2001;358:16821686.

22 National Center for Health Statistics: The Third National Health and Nutrition Examination Survey: reference manuals and reports [article online]. Available at: www.cdc. gov/nchs/data/nhanes/nh3rrm.htm [accessed April 29, 2010] 1996.

23 National Center for Health Statistics: Analytic and reporting guidelines: NHANES III [article online]. Available at: www.cdc.gov/ nchs/data/nhanes/nhanes3/nh3gui.pdf [accessed April 29, 2010] 1996.

$>24$ Perloff D, Grim C, Flack J, et al: Human blood pressure determination by sphygmomanometry. Circulation 1993;88:24602470 . 
25 National Center for Health Statistics: Laboratory procedures used for NHANES III. Available at: www.cdc.gov/nchs/data/nhanes/ nhanes3/cdrom/nchs/manuals/labman.pdf [accessed April 29, 2010] 1996.

-26 Expert Committee on the Diagnosis of Diabetes Mellitus: Report of the expert committee on the diagnosis and classification of diabetes mellitus. Diabetes Care 2003;26(suppl 1):S5-S20.

27 Haddad JG Jr, Hahn TJ: Natural and synthetic sources of circulating 25-hydroxyvitamin D in man. Nature 1973;244:515-517.

28 Hintzpeter B, Mensink GB, Thierfelder W, Muller MJ, Scheidt-Nave C: Vitamin D status and health correlates among German adults. Eur J Clin Nutr 2008;62:1079-1089.

29 Hypponen E, Boucher BJ, Berry DJ, Power C: 25-hydroxyvitamin D, IGF-1, and metabolic syndrome at 45 years of age: a cross-sectional study in the 1958 British Birth Cohort. Diabetes 2008;57:298-305.
30 Lee DM, Rutter MK, O’Neill TW, et al: Vitamin $\mathrm{D}$, parathyroid hormone and the metabolic syndrome in middle-aged and older European men. Eur J Endocrinol 2009;161: 947-954.

-31 Jorde R, Figenschau Y, Emaus N, Hutchinson M, Grimnes G: Serum 25-hydroxyvitamin D levels are strongly related to systolic blood pressure but do not predict future hypertension. Hypertension 2010;55:792-798.

32 Margolis KL, Ray RM, Van Horn L, et al: Effect of calcium and vitamin D supplementation on blood pressure: the Women's Health Initiative Randomized Trial. Hypertension 2008;52:847-855.

33 Jorde R, Sneve M, Torjesen P, Figenschau Y No improvement in cardiovascular risk factors in overweight and obese subjects after supplementation with vitamin D3 for 1 year. J Intern Med 2010;267:462-472.

34 Li YC, Kong J, Wei M, Chen ZF, Liu SQ, Cao LP: 1,25-Dihydroxyvitamin $\mathrm{D}(3)$ is a negative endocrine regulator of the renin-angiotensin system. J Clin Invest 2002;110:229238.

-35 Simpson RU, Hershey SH, Nibbelink KA Characterization of heart size and blood pressure in the vitamin D receptor knockout mouse. J Steroid Biochem Mol Biol 2007;103: 521-524.
36 Pittas AG, Lau J, Hu FB, Dawson-Hughes B. The role of vitamin $\mathrm{D}$ and calcium in type 2 diabetes. A systematic review and metaanalysis. J Clin Endocrinol Metab 2007;92: 2017-2029.

37 Talmor Y, Golan E, Benchetrit S, et al: Calcitriol blunts the deleterious impact of advanced glycation end products on endothelial cells. Am J Physiol Renal Physiol 2008; 294:F1059-F1064.

38 Talmor Y, Bernheim J, Klein O, Green J, Rashid G: Calcitriol blunts pro-atherosclerotic parameters through NFkappaB and p38 in vitro. Eur J Clin Invest 2008;38:548554.

39 Freundlich M, Quiroz Y, Zhang Z, et al: Suppression of renin-angiotensin gene expression in the kidney by paricalcitol. Kidney Int 2008;74:1394-1402.

40 Bodnar LM, Catov JM, Simhan HN, Holick MF, Powers RW, Roberts JM: Maternal vitamin $\mathrm{D}$ deficiency increases the risk of preeclampsia. J Clin Endocrinol Metab 2007;92: 3517-3522. 